\title{
Contribution of NMR spectroscopy to the mechanistic understanding of photochromism
}

\author{
S. Delbaere, ${ }^{1, \dagger}$ J. C. Micheau, ${ }^{2}$ J. Berthet, ${ }^{1}$ and G. Vermeersch ${ }^{1}$ \\ ${ }^{1}$ Laboratoire de Physique et LARMN, UMR CNRS 8009, Faculté de Pharmacie, Université de Lille 2, F-59006 Lille, France \\ ${ }^{2}$ Laboratoire IMRCP, UMR CNRS 5623, Université Paul Sabatier, F-31062 Toulouse, France
}

\begin{abstract}
Along with classical UV-Visible spectroscopy allowing for the determination of intrinsic properties $\left(\lambda_{\max }, \varepsilon\right)$, multinuclear NMR spectroscopy is a promising and useful tool for studying photochromic reactions. UV irradiation of the initial structure leads to the formation of photoproducts, which can be structurally identified by $1 \mathrm{D}$ and 2D NMR experiments. The kinetics of thermal back reaction are monitored by directly and separately measuring the concentrations of each long-living species at regular time intervals in NMR spectra. A plausible reaction mechanism can therefore be proposed. Based on this mechanism, the kinetic analysis and the study of the effects of temperature lead to the determination of the kinetic and thermodynamic parameters (rate coefficients, enthalpy and entropy of activation) of the photochromic system under investigation. This process has been applied to several photochromic families, spirooxazines and benzo- and naphtho-pyrans.
\end{abstract}

\section{INTRODUCTION}

Organic photochromic materials have been the subject of intense investigations because of the wide variety of their potential applications which include ophthalmic and sunglass lenses, optical recording and solar energy storage [1-4]. Spironaphthoxazines [5] and benzoand naphthopyrans [6] are classes of photochromic compounds that have progressively replaced spiropyrans due mainly to their ability to impart intense photocoloration in appropriate application media, their good photofatigue resistance and the relative ease with which their materials can be synthesised. They give colourless or weakly coloured solutions, which become intensely blue, or range from orange to red, respectively, under UV light. Such a change in the absorption spectrum is characteristic of the formation, after $\mathrm{C}_{\mathrm{sp} 3}-\mathrm{O}$ bond cleavage and isomerisation, of one or more photoproducts called photomerocyanines. These open structures revert to the initial closed form through a thermally or a photochemically induced ring-closure reaction.

Typically, UV-Visible spectroscopy has been used to study photochromism, as it represents a useful source of mechanistic information: maximal absorption wavelength, molar extinction coefficient, quantum yields, rate constant of bleaching can be determined [5, 7]. Nevertheless, if more than one photomerocyanine structure is formed, spectral overlapping between several photoisomers impedes the unequivocal extraction of parameters. This method can then be revealed as nonsufficient because it is difficult to determine how many and which photoproducts have been formed. Consequently, along with classical UV-Visible spectroscopy,

†E-mail: sdelbaer@pharma.univ-lille2.fr multinuclear NMR spectroscopy can be considered as a promising and useful tool for studying photochromic reactions. Indeed, the proton spectrum of the initial closed form has characteristic resonances. Comparison with a spectrum recorded after irradiation shows the decrease in its signals while the new ones which are detected, characterise photoproducts. Although time resolution and sensitivity are lower than with UV spectroscopy, it is possible to determine the number, structure and concentration of new forms. Another very interesting advantage is the possibility to monitor their quantitative evolution.

In the present paper, we wish to present recent results, obtained by NMR studies of both families: spirooxazines and benzo- and naphthopyrans. After UV irradiation, the photoproducts were identified by 1D and 2D NMR analysis. The kinetics of thermal evolution in the dark were monitored by measuring the concentrations of each long-living species at regular time intervals.

\section{EXPERIMENTAL DETAILS}

The photochromic spirooxazine Spo studied is an Aldrich product (ref. 32,254-7. 1, 3-dihydro-1, 3, 3-trimethylspiro[2H-indole-2, $3^{\prime}$-[3H]-naphth[2, 1-b] [1,4]oxazine]). [2H]-benzo- and [3H]-naphthopyrans (FC) were synthesised according to standard procedures [8]. They were used without further purification to prepare $10^{-2} \mathrm{M}$ toluene- $\mathrm{d}_{8}$, acetone- $\mathrm{d}_{6}$ or acetonitrile- $\mathrm{d}_{3}$ solutions.

UV or visible irradiation of the samples in the NMR tube were performed in a home-built apparatus. The emission spectrum of a $1000 \mathrm{~W}$ Xe-Hg high-pressure filtered short-arc lamp (Oriel), was focused on the end of 
(A)

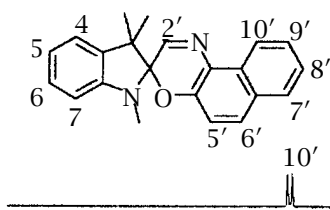

(B)

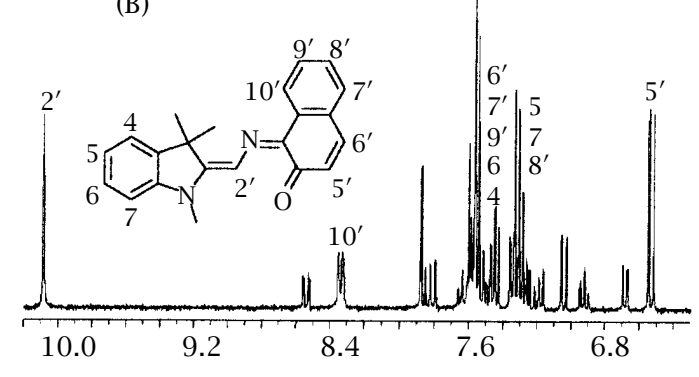

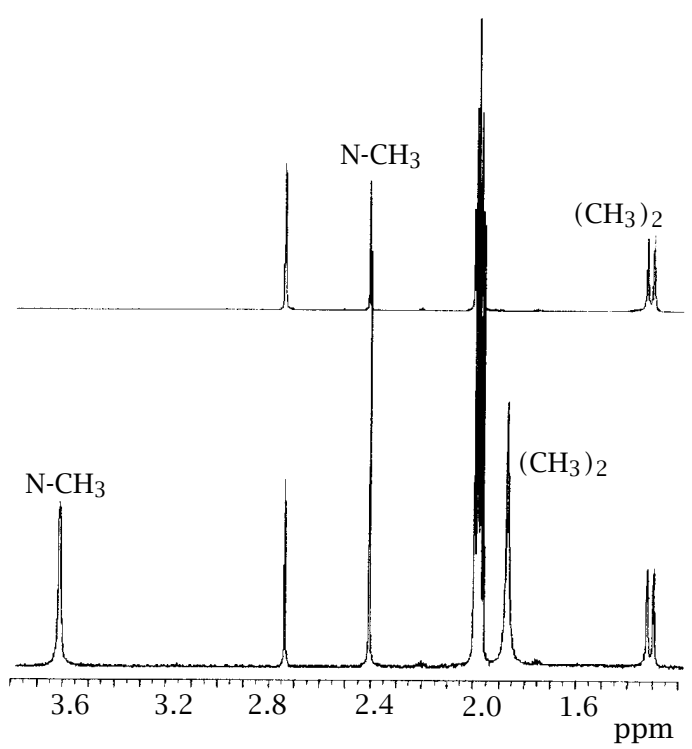

Figure $1 .{ }^{1} \mathrm{H}$ NMR spectra (A) before and (B) after UV irradiation of spirooxazine ( $T=228 \mathrm{~K}$, acetonitrile- $\left.\mathrm{d}_{3}\right)$.

a silica light-pipe (length $6 \mathrm{~cm}$, diameter $8 \mathrm{~mm}$ ), leading the light to the spinning sample tube, inserted in a quartz dewar. The temperature of the sample was controlled with a variable temperature unit (B-VT1000Bruker, 123 to $423 \mathrm{~K}$, T range). The filters used were the Schott 011FG09: $259<\lambda<388 \mathrm{~nm}$ with $\lambda_{\max }=330 \mathrm{~nm}$ and $\mathrm{T}=79 \%$ and the Oriel 3-74: $\lambda>400 \mathrm{~nm}$ for UV and visible irradiation respectively.

1D and 2D NMR spectra were obtained on a Bruker (DPX 300 or AC 300) NMR spectrometer equipped with a BBI probehead fitted with an actively shielded z-gradient coil to deliver pulsed field gradients or with a QNP probehead (for ${ }^{19} \mathrm{~F}$ NMR spectroscopy).

For kinetic analysis, concentrations of photoproducts were deduced from the measurements of integrals in each spectrum recorded at regular times during irradiation or thermal bleaching. From the number of species and their evolution, a tentative mechanism was proposed. To solve the differential kinetic equations deduced from this mechanism and to extract the rate constants, we used home-made software [911]. All the kinetic parameters were fitted automatically using an iterative algorithm of the Powell type, designed to minimise the residual quadratic error $\chi^{2}=$ $\sum_{\mathrm{n}} \sum_{\mathrm{m}}\left(\mathrm{Y}_{\mathrm{cal}}-\mathrm{Y}_{\mathrm{obs}}\right)^{2}$ between the experimental and the calculated curves ( $\mathrm{n}$ is the number of experimental data points and $m$ the number of kinetic curves). For the sake of simplicity, too-small non-significant parameters were removed as long as a systematic misfit between the model and the experiments was not observed.

\section{RESULTS AND DISCUSSION}

3.1. Behaviour of the Spirooxazine (Spo). After irradiating the Spo, ${ }^{1} \mathrm{H}$ NMR spectra (Figure 1) were recorded in the dark at regular intervals ( $t$ ) and at

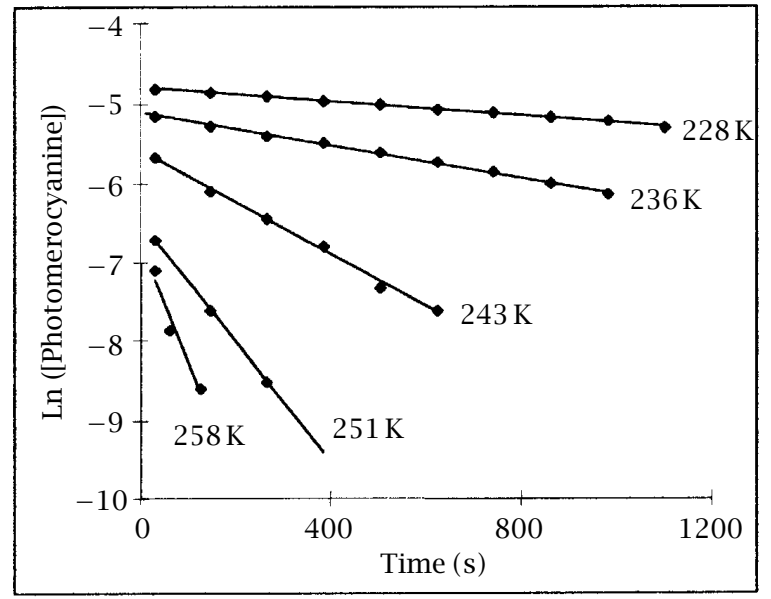

Figure 2. Variable temperature kinetic analysis of photomerocyanine thermal evolution after UV irradiation of Spo in acetonitrile- $\mathrm{d}_{3}$.

different temperatures (T). In the spectra, we still observed some small signals corresponding to the residual closed form and other intense signals (which decreased during thermal bleaching) corresponding to the photoproducts. The integration of some characteristic signals in each spectrum made it possible to follow the time-evolution of the concentrations. During the thermal decay of photoproducts, the concentration of the closed initial form increases. The decay follow a firstorder kinetic. The kinetic rate constants of bleaching $\mathrm{k}_{\Delta}$ were calculated from the slope of the Ln [photomerocyanine] vs. time straight lines (Figure 2).

In acetonitrile- $\mathrm{d}_{3}$ and acetone- $\mathrm{d}_{6}$, only one type of merocyanine was detected. However, a more careful look by the use of ${ }^{1} \mathrm{H}$ NOE measurements indicated the 

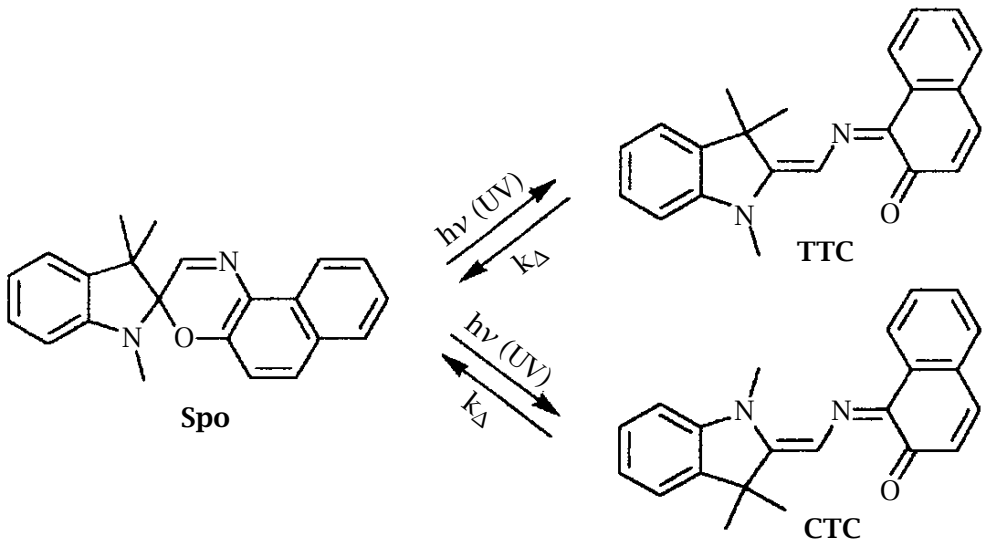

Scheme 1. Photochromic equilibrium in spirooxazine (Spo).

Table 1. First-order kinetic rate constants of thermal bleaching of photomerocyanines at various temperatures (in $\mathrm{s}^{-1}$ ).

\begin{tabular}{ccc}
\hline acetonitrile- $\mathrm{d}_{3}$ & acetone- $\mathrm{d}_{6}$ & toluene- $\mathrm{d}_{8}$ \\
\hline${ }^{228} \mathrm{k}_{\Delta}=4.510^{-4}$ & & ${ }^{228} \mathrm{k}_{\Delta}=1.610^{-4}$ \\
${ }^{236} \mathrm{k}_{\Delta}=1.010^{-3}$ & & (TTC) \\
${ }^{243} \mathrm{k}_{\Delta}=3.310^{-3}$ & ${ }^{228} \mathrm{k}_{\Delta}=1.810^{-4}$ & ${ }^{228} \mathrm{k}_{\Delta}=1.810^{-4}$ \\
${ }^{251} \mathrm{k}_{\Delta}=1.010^{-2}$ & & (CTC) \\
${ }^{258} \mathrm{k}_{\Delta}=1.510^{-2}$ &
\end{tabular}

presence of two isomers, (Scheme 1) with identical resonances, the Trans-Transoid-Cis (TTC), more highly concentrated, and the Cis-Transoid-Cis (CTC) [12, 13].

This result was confirmed by studying Spo behaviour in toluene solutions. Such a non-polar solvent made it possible to distinguish the signals of TTC from those belonging to CTC, and consequently, to measure the rate constant of bleaching for each of them [14].

Kinetic values are gathered in Table 1 . Experiments in acetonitrile solution were performed at different temperatures to determine the activation energy of thermal bleaching using the Arrhenius equation (Ea = $63 \mathrm{~kJ} . \mathrm{mol}^{-1}$ ). By spectrophotometrical measurements, Chu determined a thermal barrier equal to $82 \mathrm{~kJ} \cdot \mathrm{mol}^{-1}$ for Spo in ethanol [5]. In the same way, Maurel et al. have recently calculated a theoretical value of 91 (in the gas phase) and $101 \mathrm{~kJ} \cdot \mathrm{mol}^{-1}$ (in ethanol) [15]. The similarity of the reported order of magnitude supports the validity of our experimental procedure. In toluene solution, a slight but significant difference appears between the thermal behaviour of the TTC and CTC merocyanines. The TTC being (as expected) the most stable.

\subsection{Behaviour of the Naphtho- and Benzo-Pyran}

Family. The same procedure was applied to study the behaviour of the naphtho- and benzo- pyran family. These compounds, also known as chromenes, possess only aromatic or ethylenic protons, making it difficult to distinguish easily between all the possible photo-
Table 2. Structures of the naphtho- and benzo- pyrans under investigation.

\begin{tabular}{lccccclll}
\hline & $R 1$ & $R 2$ & $R 3$ & $R 4$ & $R 5$ & $X$ \\
\hline Naphthopyrans & $\mathrm{F}$ & $\mathrm{H}$ & $\mathrm{H}$ & $\mathrm{F}$ & $\mathrm{H}$ & $\mathrm{CH}$ & FC-1 [16] \\
& $\mathrm{H}$ & $\mathrm{F}$ & $\mathrm{H}$ & $\mathrm{H}$ & $\mathrm{F}$ & $\mathrm{CH}$ & FC-2 \\
$\mathrm{H}$ & $\mathrm{H}$ & $\mathrm{F}$ & $\mathrm{H}$ & $\mathrm{H}$ & $\mathrm{CH}$ & FC-3 [17] \\
& $\mathrm{F}$ & $\mathrm{H}$ & $\mathrm{H}$ & $\mathrm{H}$ & $\mathrm{H}$ & $\mathrm{N}$ & FC-4 \\
& $\mathrm{H}$ & $\mathrm{CF}$ & $\mathrm{H}$ & $\mathrm{H}$ & $\mathrm{H}$ & $\mathrm{CH}$ & FC-5
\end{tabular}

products. To overcome this difficulty, each of the compounds investigated (Table 2) was fluoro-substituted, in order to use this nucleus as an NMR molecular probe.

After UV irradiation of compounds with symmetrical phenyl groups, (FC-1, FC-2, FC-6 and FC-7) (Figures 3 and 4) several new signals were detected. NMR experiments show that in contrast to the closed form, all the photoproducts possess unequivalent fluoro-phenyl groups. This effect is due to the $\mathrm{sp}^{2}$ hybridisation of the previous spiro-carbon giving rise to two different isomers, the transoid-cis (TC) and the transoid-trans (TT) which were identified as major photoproducts during the thermal evolution. When irradiating disymmetrical molecules (FC-3, FC-4 and FC-5), the four expected isomers of photomerocyanines: TTC, CTC, CTT and TTT were identified (Figure 5). During each experiment and for each system studied (FC-1 to FC-7), a supplementary unprecedented structure (A) was detected and characterised as an allenyl- naphthol or phenol [19-21].

\subsubsection{Thermal bleaching}

By recording ${ }^{19} \mathrm{~F}$ NMR spectra at regular time intervals after irradiation, the kinetics of thermal bleaching were 

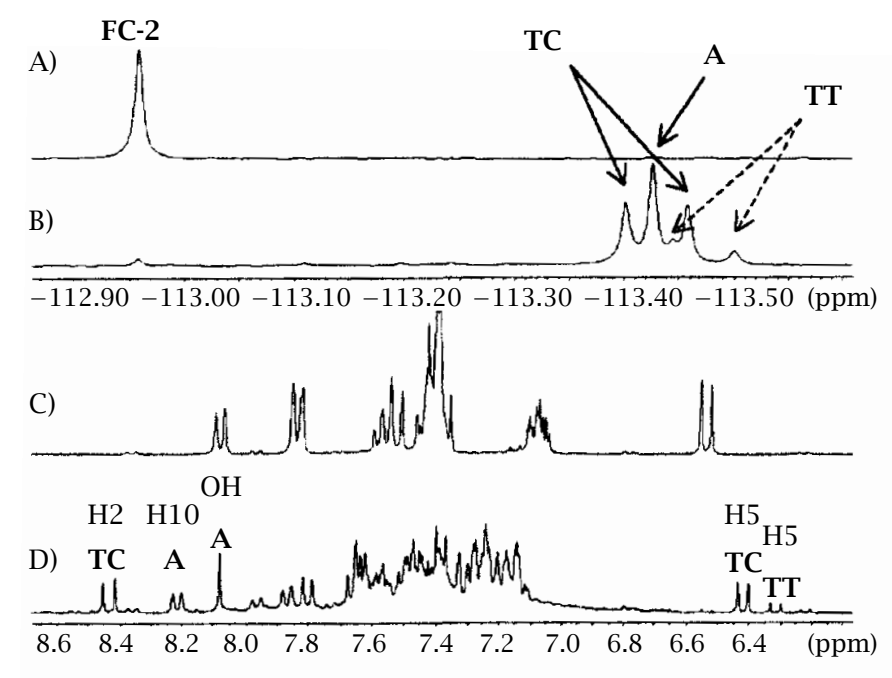

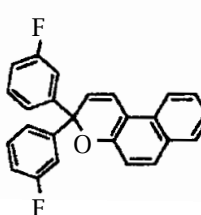

FC-2

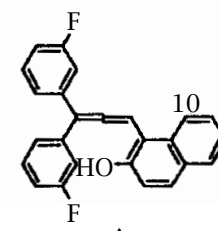

A

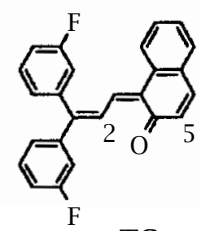

TC

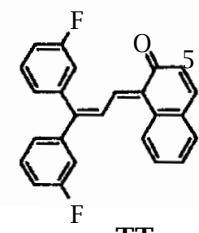

TT

Figure 3. (A) and (B): ${ }^{19} \mathrm{~F} N M R$ spectra before and after UV irradiation. (C) and (D): ${ }^{1} \mathrm{H} N M R$ spectra before and after UV irradiation of 3,3-di-(3-fluorophenyl)-[3H]-naphtho[2,1-b]pyran (FC-2) at $T=228 \mathrm{~K}$, in acetonitrile- $\mathrm{d}_{3}$.

Table 3. First-order kinetic rate constants of chromene thermal bleaching, $\mathrm{k}_{\Delta}$ in $\mathrm{s}^{-1}$, measured at $228 \mathrm{~K}$. (-): too slow to be detectable within our recording time.

\begin{tabular}{|c|c|c|c|c|c|c|}
\hline \multicolumn{3}{|c|}{ Transoid-Cis type } & \multicolumn{2}{|c|}{ Transoid-Trans type } & \multicolumn{2}{|c|}{ Allene } \\
\hline & \multicolumn{2}{|c|}{$\mathrm{TC} \rightarrow \mathrm{FC}$} & \multicolumn{2}{|c|}{$\mathrm{TT} \rightarrow \mathrm{TC}$} & \multicolumn{2}{|c|}{$\mathrm{A} \rightarrow \mathrm{TC}$} \\
\hline FC-1 & \multicolumn{2}{|c|}{$1.010^{-4}$} & \multicolumn{2}{|c|}{$5.910^{-6}$} & \multicolumn{2}{|c|}{$9.310^{-4}$} \\
\hline FC-2 & \multicolumn{2}{|c|}{$0.3110^{-4}$} & \multicolumn{2}{|c|}{$7.010^{-6}$} & \multicolumn{2}{|c|}{$3.610^{-4}$} \\
\hline FC-6 & \multicolumn{2}{|c|}{$0.3510^{-4}$} & \multicolumn{2}{|c|}{-} & \multicolumn{2}{|c|}{-} \\
\hline \multirow[t]{2}{*}{ FC-7 } & \multicolumn{2}{|c|}{$8.410^{-4}$} & \multicolumn{2}{|c|}{$2.110^{-6}$} & \multicolumn{2}{|c|}{$0.0210^{-4}$} \\
\hline & TTC $\rightarrow$ FC & $\mathrm{CTC} \rightarrow \mathrm{FC}$ & $\mathrm{CTT} \rightarrow \mathrm{CTC}$ & $\mathrm{TTT} \rightarrow \mathrm{TTC}$ & $\mathrm{A} \rightarrow \mathrm{TTC}$ & $\mathrm{A} \rightarrow \mathrm{CTC}$ \\
\hline FC-3 & $0.1210^{-4}$ & $0.0210^{-4}$ & - & - & $1.410^{-4}$ & $0.9410^{-4}$ \\
\hline FC-4 & $3.610^{-4}$ & $2.710^{-4}$ & - & - & $2.810^{-4}$ & $1.610^{-4}$ \\
\hline FC-5 & $1.210^{-4}$ & $0.5310^{-4}$ & - & - & $2.410^{-4}$ & $2.210^{-4}$ \\
\hline
\end{tabular}

determined, and the rate constants and thermodynamic parameters calculated. A typical example of thermal bleaching kinetics is shown on Figure 6 .

Figure 6 illustrates the evolution of the concentration of the various isomers during the thermal bleaching. The closed initial structure (FC-5) increases while the allenyl-naphthol A follows a monoexponential decay. The time-dependent profiles of TTC and CTC are bi-exponential curves. Transoid-Trans type isomers, CTT and TTT, seem to remain stable during the recording time, but they disappear after a longer period.

Scheme 2 shows a consecutive reaction from the allenyl structure A via the Transoid-Cis type isomer TC, to the closed initial form FC $[16,17]$. This decay occurs via a [1,5]-sigmatropic hydrogen shift to the TC-type molecule (TTC and CTC), which is the only structure able to be converted directly into FC by a single bondrotation. TC-type molecules then act as a key intermediate in the pathway from A to FC. On the contrary, the TT-type isomers (CTT and TTT) needing a double bond-rotation for reversion do not proceed directly to FC, thus justifying their apparent thermal stability. In fact, they are in equilibrium with TC-type molecules.

In the case of benzopyran derivatives (FC-6 and FC-7), allenyl-phenol also evolves towards the TC isomer [19]. However, its thermal conversion is drastically slowed down, because of the greater stability of phenol compared to naphthol (see Table 3). 

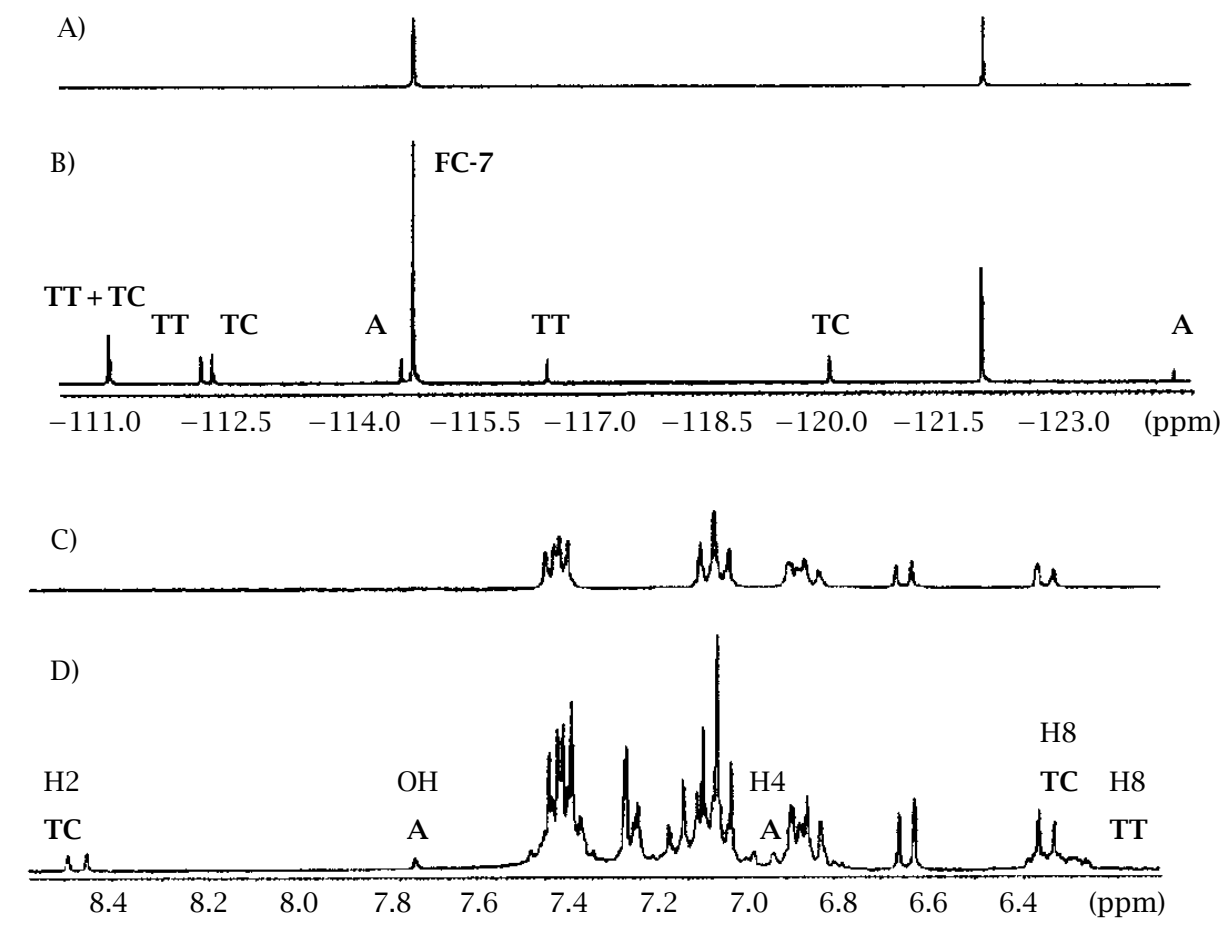

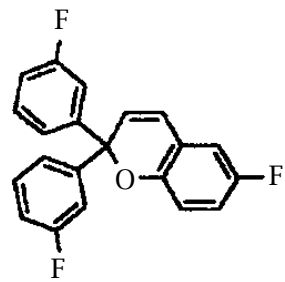

FC-7

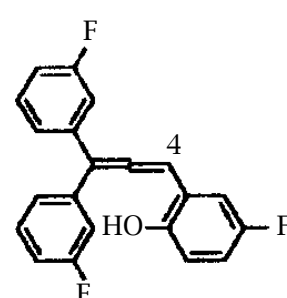

A

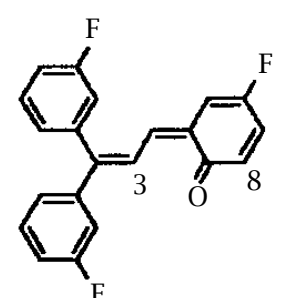

TC

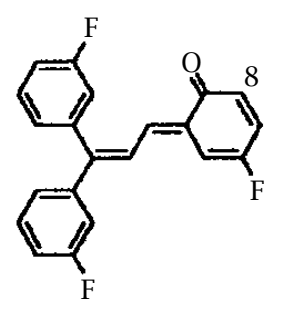

TT

Figure 4. (A) and (B): ${ }^{19} \mathrm{~F} N M R$ spectra before and after UV irradiation. (C) and (D): ${ }^{1} \mathrm{H} N M R$ spectra before and after UV irradiation of 2,2-di-(4-fluorophenyl)-6-fluoro-[3H]-1-benzopyran (FC-7) at $T=228 \mathrm{~K}$ in acetonitrile- $\mathrm{d}_{3}$. ble 3 .

Optimised kinetic parameters are reported in Ta-

\subsubsection{Evolution under UV and Visible irradiation}

To understand the photoreaction mechanism, benzopyran FC-6 was kinetically monitored during UV, then during visible irradiation (Figure 7).

Analysis of kinetics shows that UV irradiation of the closed form (FC-6) leads mainly to the TC isomer (FC-6 $+\mathrm{h} v_{(\mathrm{UV})} \rightarrow$ TC). But, two other parallel pathways were also detected towards TT and A (FC-6 $+\mathrm{h} \nu_{(\mathrm{UV})} \rightarrow$ TT) and (FC-6 + h $\nu_{(\mathrm{UV})} \rightarrow$ A). Another important process is the photoreversion of TC to the closed initial structure (TC $+\mathrm{h} v_{(\mathrm{UV})} \rightarrow$ FC-6). Photoisomerisation be- tween TT and TC also occurs (TC $\left.+\mathrm{h} \nu_{(\mathrm{UV})} \rightarrow \mathrm{TT}\right)$ and $\left(\mathrm{TT}+\mathrm{h} \nu_{(\mathrm{UV})} \rightarrow \mathrm{TC}\right)$. On the contrary, reaction from TC to $\mathbf{A}$ is slow and $\mathrm{A}$ is photostable $\left(\mathrm{A}+\mathrm{h} v_{(\mathrm{UV})} \rightarrow\right.$ no reaction) (Scheme 3 ).

The same investigation procedure was applied during visible light irradiation. Examination of kinetics shows that photomerocyanines are (as expected) the only photoreactive species. TT is isomerised to TC $\left(\mathrm{TT}+\mathrm{h} \nu_{(\mathrm{VIS})} \rightarrow \mathrm{TC}\right)$ and TC to FC-6 (TC $+\mathrm{h} \nu_{(\mathrm{VIS})} \rightarrow$ FC-6). Nevertheless, the main process is a conversion of TC to allenyl-phenol by a [1.5]-hydrogen shift (TC $+\mathrm{h} \nu_{\text {(VIS) }} \rightarrow$ A). This sigmatropic rearrangement is allowed from TC due to the helical trienic open chain, in which continuous overlap can be maintained. Such geometrical requirements are not possible within the TT structure. 

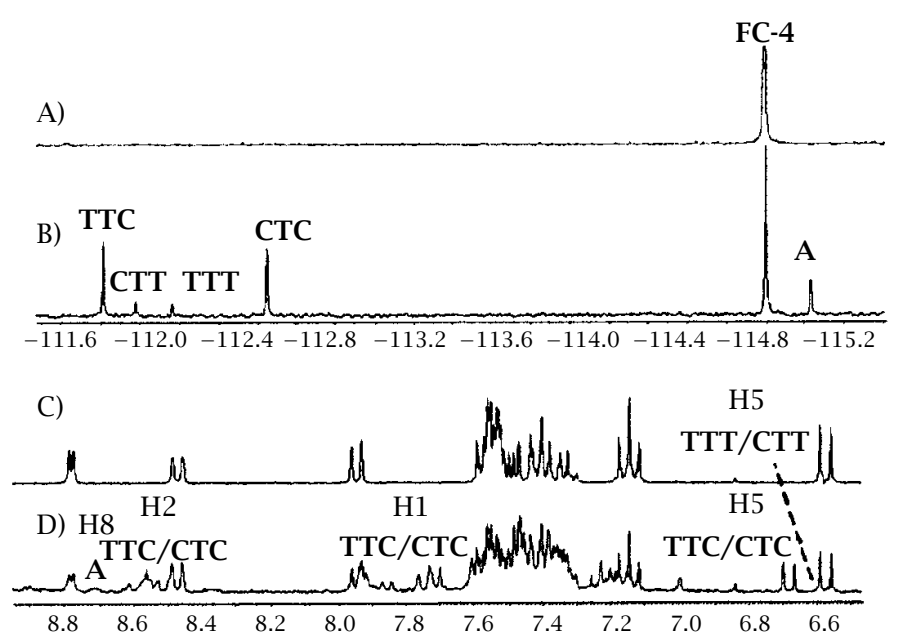

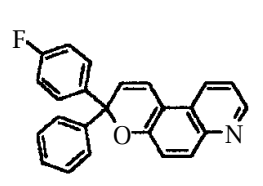

FC-4<smiles></smiles>

CTC<smiles>O=C1SCC2=c3cccnc3=CC1C(=O)C2=CC=C(c1ccccc1)c1ccc(F)cc1</smiles>

CTT

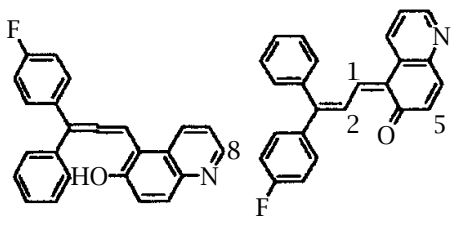

A

TTC

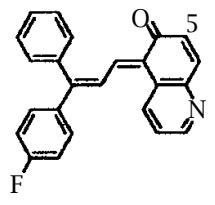

TTT

Figure 5. (A) and (B): ${ }^{19} \mathrm{~F} N M R$ spectra before and after UV irradiation. (C) and $(D):{ }^{1} \mathrm{H} N M R$ spectra before and after $U V$ irradiation of 8-(4-fluorophenyl)-8-phenyl-[8H]-pyrano[3,2-f]quinoline (FC-4) at $T=228 \mathrm{~K}$ in $\mathrm{CD}_{3} \mathrm{CN}$.

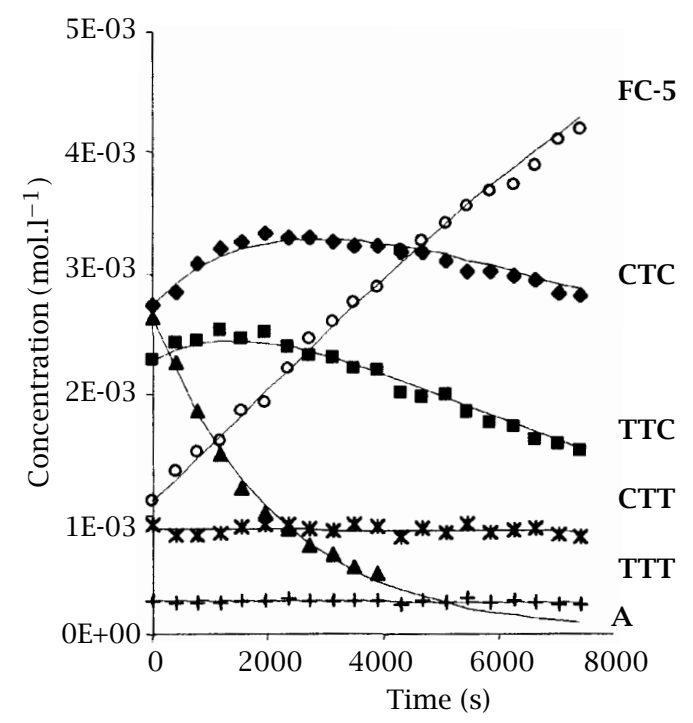

Figure 6. Typical thermal bleaching kinetics recorded at $228 \mathrm{~K}$ after irradiation of 3-(3-trifluoromethyl)-3-phenyl-[3H]naphtho[2,1-b]pyran (FC-5). Solid lines correspond to the numerical fitting using the Scheme 2 as a mechanistic model. 
<smiles>Cc1ccc2c(c1C)C=CC(C)(C)O2</smiles>

FC

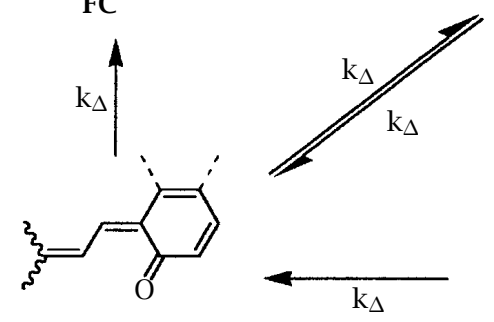

CTC/TTC<smiles>CC=CC=C1C(=O)C=CC(C)=C1C</smiles>

CTT/TTT<smiles>CC(C)=C=Cc1c(O)ccc(C)c1C</smiles>

A<smiles></smiles>

FC<smiles>CC(C)=CC=C1C(=O)C=CC(C)=C1C</smiles>

CTT/TTT

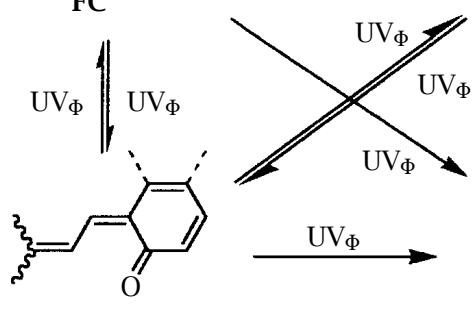

CTC/TTC

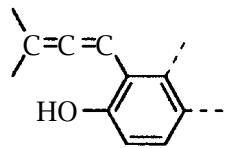

A

Scheme 2. Mechanism of thermal bleaching in naphthoand benzo- pyrans.

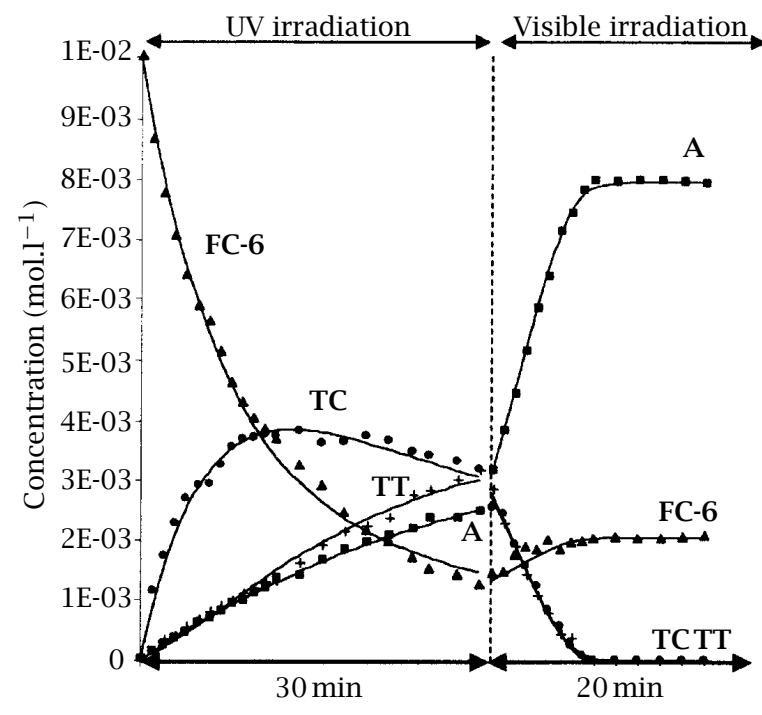

Figure 7. Time-evolution concentrations at $228 \mathrm{~K}$ under 30 minutes of UV irradiation, followed by 20 minutes of visible light of 2,2-di(4-fluorophenyl)-6-methoxy-2H-1chromene (FC-6) [18].

\section{CONCLUSION}

NMR spectroscopy is a promising tool for studying photochromic compounds: the number, the structure and the concentration of each photomerocyanine, whatever the initial structure of the photochromic compound (spirooxazine, [3H]-naphthopyrans or [2H]benzopyrans) can be unambiguously determined. Moreover, kinetic studies are considerably improved by direct NMR monitoring of the individual concentrations of each photoproduct. The most plausible reaction mechanisms can then be tested. The kinetic rate constants can be extracted while activation parameters can be obtained from temperature effect measurements.

Scheme 3. Mechanism of photocoloration of naphtho- and benzo- pyrans under UV irradiation.<smiles>Cc1ccc2c(c1C)C=CC(C)(C)O2</smiles>

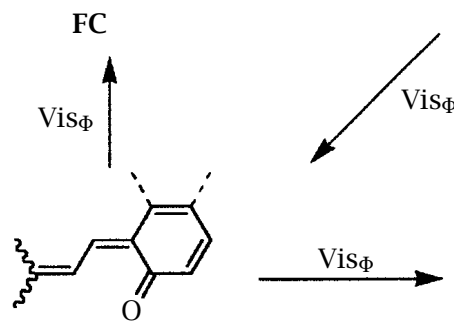

CTC/TTC<smiles>CC(C)=CC=C1C(=O)C=CC(C)=C1C</smiles>

CTT/TTT
Scheme 4. Mechanism of photo-bleaching in naphtho- and benzo- pyrans under visible irradiation.

By monitoring chromene evolution during UV then visible irradiations, an unexpected conversion of the TC-type photomerocyanine to an allenyl structure (A) was detected and its involvement in the global mechanism clarified. Moreover, photo and thermal bleaching kinetics have also demonstrated that the Transoidtrans structure (TT) can not return directly to its initial closed form. Its disappearance requires isomerisation towards TC, the only photomerocyanine able to convert to FC by a single bond rotation.

\section{ACKNOWLEDGMENTS}

The $300 \mathrm{MHz}$ NMR facilities were funded by the Région Nord-Pas de Calais (France), the Ministère de la Jeunesse, de l'Education Nationale et de la Recherche (MJENR) and the Fonds Européens de Développement 
Régional (FEDER). The authors thank Dr. M. Campredon (Université de la Méditerranée) for samples of benzo and naphthopyrans. Part of this collaborative work was performed within the framework of the "Groupe de Recherche: Photochromes Organiques, Molécules, Mécanismes, Modèles”, GDR CNRS n²466.

\section{REFERENCES}

[1] R. C. Bertelson, Photochromism, (G. H. Brown, Ed.), Wiley, New York, 1971.

[2] N. Y. C. Chu, in Photochromism: Molecules and Systems, (H. Dürr and H. Bouas-Laurent, Eds.), Elsevier, Amsterdam, 1990, chap. 10-24.

[3] R. Guglielmetti, in Photochromism: Molecules and Systems, H. Dürr and H. Bouas-Laurent (Eds.), Elsevier, Amsterdam, 1990, chap. 8-23.

[4] B. Van Gemert, in Organic Photochromic and Thermochromic Compounds, (J. C. Crano and R. J. Guglielmetti, Eds.), Plenum Press, New-York, 1999, Chap. 4.

[5] N. Y. C. Chu, Can. J. Chem. 61 (1983), 300.

[6] R. S. Becker and J. Michl, J. Am. Chem. Soc. 88 (1966), 5931.

[7] G. Ottavi, G. Favaro, and V. Malatesta, J. Photochem. Photobiol. A: Chem 115 (1998), 123; G. Ottavi, F. Ortica, and G. Favaro, Int. J. Chem. Kinet. 31 (1999), 303.

[8] J.-L. Pozzo, A. Samat, R. Guglielmetti, R. Dubest, and J. Aubard, Helv. Chim. Acta 80 (1997), 725.

[9] M. Minoux, in Programmation Mathématique, (Dunod, Ed.), Bordas, Paris, 1983, Vol. 1, 95.
[10] K. Kaps and P. Rentrop, Comp. Chem. Eng. 8 (1984), 393.

[11] M. H. Deniel, D. Lavabre, and J. C. Micheau, in Organic Photochromic and Thermodynamic Compounds, (J. C. Crano and R. J. Guglielmetti, Eds.), Plenum Press, New-York, 1999, Vol. 2, 167.

[12] S. Nakamura, K. Uchida, A. Murakami, and N. Irie, J. Org. Chem. 58 (1993), 5543.

[13] S. Delbaere, C. Bochu, N. Azaroual, G. Buntinx, and G. Vermeersch, J. Chem. Soc. Perkin Trans. 2 (1997), 1499.

[14] J. Berthet, S. Delbaere, V. Lokshin, C. Bochu, A. Samat, R. Guglielmetti, and G. Vermeersch, Photochem Photobiol. Sci. 1 (2002), 333.

[15] F. Maurel, J. Aubard, M. Rajzmann, R. Guglielmetti, and A. Samat, J. Chem Soc. Perkin Trans. 2 (2002), 1307.

[16] S. Delbaere, B. Luccioni-Houze, C. Bochu, Y. Teral, M. Campredon, and G. Vermeersch, J. Chem Soc. Perkin Trans. 2 (1998), 1153.

[17] S. Delbaere, J.-C. Micheau, Y. Teral, C. Bochu, M. Campredon, and G. Vermeersch, Photochem Photobiol. 74 (2001), 694.

[18] S. Delbaere, J.-C. Micheau, and G. Vermeersch, J. Org. Chem. 68 (2003), 8968.

[19] S. Delbaere, J.-C. Micheau, and G. Vermeersch, Org. Lett. 18 (2002), 3143.

[20] S. Delbaere and G. Vermeersch, Tet. Lett. 44 (2003), 259.

[21] S. Delbaere and G. Vermeersch, J. Photochem. Photobiol. A: Chem. 159 (2003), 227. 


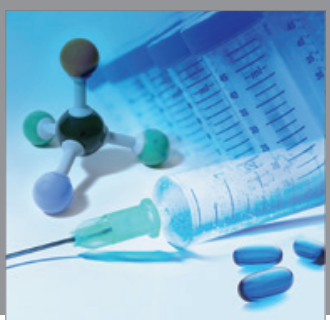

International Journal of

Medicinal Chemistry

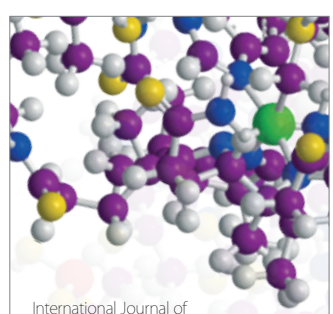

Carbohydrate Chemistry

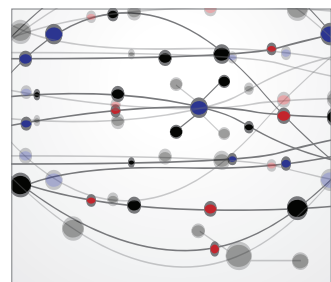

The Scientific World Journal
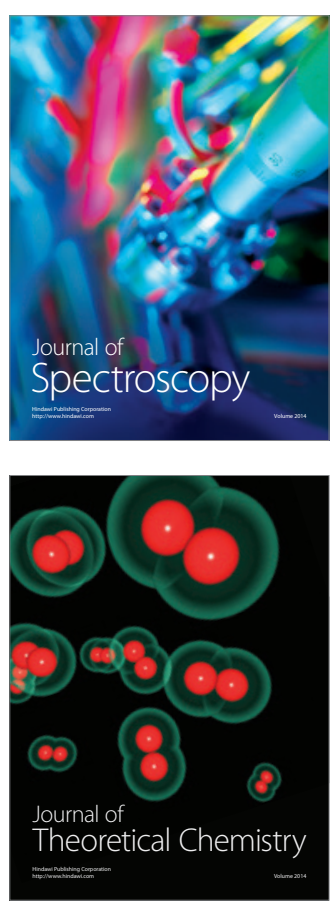
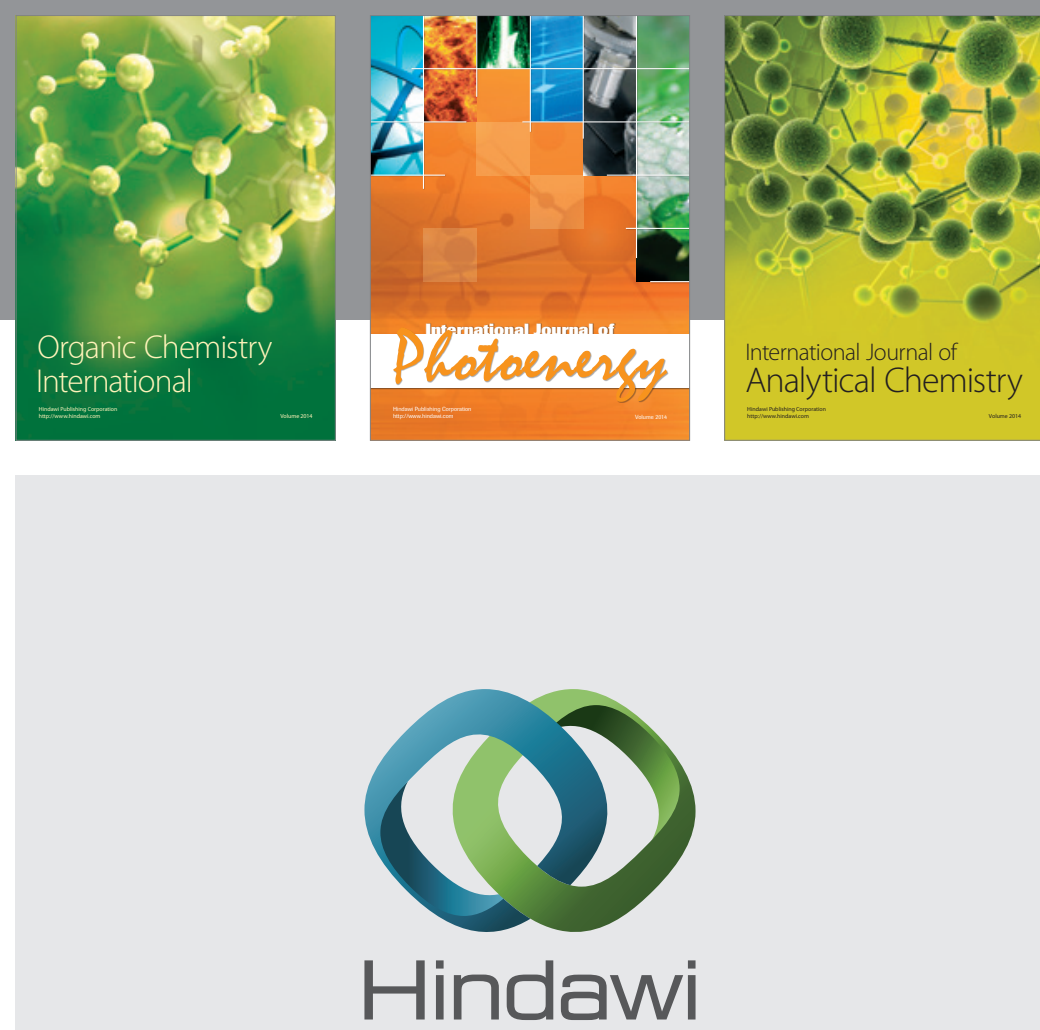

Submit your manuscripts at

http://www.hindawi.com
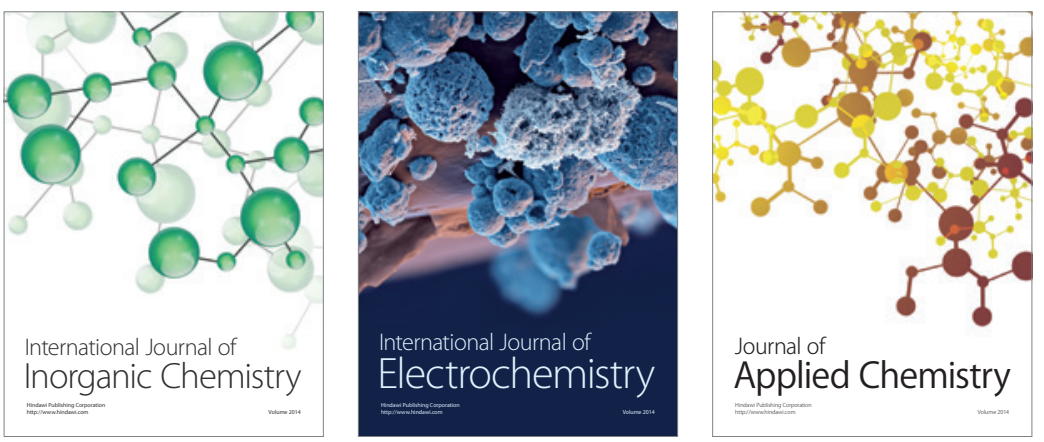

Journal of

Applied Chemistry
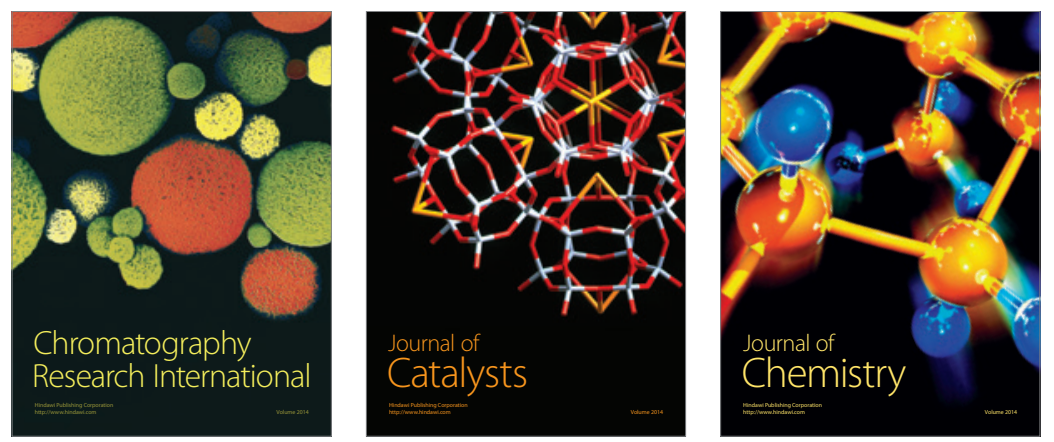
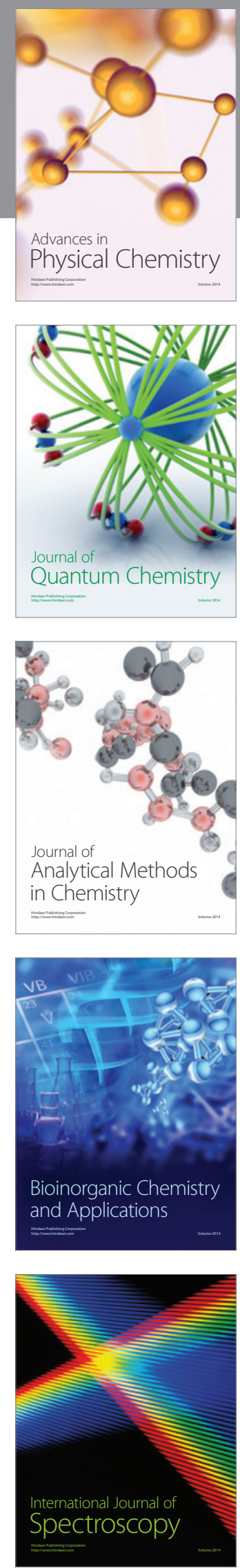